\title{
Segunda Temporada de Pesca de Anchoveta 2016
}

\author{
Un desafío para el manejo pesquero
}

Elaborado por la Dirección Científica de

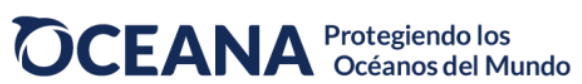

Perú, 14 de noviembre 2016 


\section{INTRODUCCIÓN}

El Ministerio de la Producción (PRODUCE) autorizó el inicio de la segunda temporada de pesca del stock norte-centro de la anchoveta mediante la Resolución Ministerial $\mathrm{N}^{\circ} 440$ 2016-PRODUCE (Ver aquí). Aunque el reporte del Instituto del Mar del Perú (IMARPE) "Situación del Stock Norte - Centro de la Anchoveta Peruana al 01 de noviembre de 2016 y Alternativas de Explotación para la Segunda Temporada de Pesca 2016" aún no está disponible al público, es posible presentar algunas consideraciones sobre la próxima temporada de pesca.

Es importante resaltar que el stock, y en consecuencia la actividad pesquera, viene de un periodo de baja productividad, iniciado alrededor del invierno del 2014. Esto es consecuencia de cambios oceanográficos y climáticos asociados a El Niño y al ingreso de aguas oceánicas que alteraron la condición y recuperación de la anchoveta, así como de otras especies propias del Ecosistema Marino de Humboldt. Por ello no se abrió la segunda temporada del año 2014 y la primera temporada del 2016 tuvo un cierre prematuro. Asimismo, las cuotas de pesca fueron menores en este periodo. 


\section{BIOMASA Y CUOTA DE PESCA}

Según la RM 440-2016-PRODUCE la biomasa evaluada correspondiente al stock nortecentro (desde el norte del país hasta los $16^{\circ}$ de latitud sur) es igual a 6,86 millones de toneladas. Este valor refleja una notable recuperación relacionada con la mejora paulatina de las condiciones ambientales. Es muy probable que el cierre temprano de la temporada anterior (al $50 \%$ de la cuota establecida) haya permitido la supervivencia y posterior reproducción de una porción significativa del stock.

La cuota de pesca para esta temporada se ha fijado en dos millones de toneladas, lo cual representa alrededor del $30 \%$ del stock estimado. De acuerdo a la información brindada por IMARPE en la presentación pública realizada el 9 de noviembre en la sede de PRODUCE, esta cuota se encuentra dentro de los parámetros que aseguran la sostenibilidad del recurso.

De esta manera se habría estimado que esta cuota garantiza un stock de cuatro millones de individuos reproductores al inicio de la siguiente temporada reproductiva, en un escenario ambiental neutral a ligeramente positivo.

\section{JUVENILES}

Según la última evaluación de IMARPE, los individuos juveniles (menos de $12 \mathrm{~cm}$ de longitud) comprenden el $86 \%$ del stock, con un peso equivalente a casi la mitad (49\%) del total. La última vez que se encontraron proporciones tan altas de juveniles fue a finales del año 2014 (97\%), factor que unido a una biomasa muy baja, no permitió la apertura de la segunda temporada de pesca de dicho año.

Esto refleja que el stock se viene recuperando rápidamente. Sin embargo, en términos prácticos una alta proporción de juveniles significa que la probabilidad de pescarlos es muy alta. De la biomasa total, 3,42 millones de toneladas serían adultos. Lo que, de acuerdo a la cuota fijada en dos millones, significa que para no afectar a los juveniles 
tres de cada cinco anchovetas adultas deberían ser pescadas, escenario que resulta poco probable.

Desafortunadamente no existen tecnologías prácticas disponibles a nivel local para evitar la captura de anchoveta por debajo de la talla mínima legal $(12 \mathrm{~cm})$. La principal herramienta para reducir la captura de juveniles es el cierre preventivo de las zonas donde se hayan detectado.

Considerando que la pesca de juveniles es prácticamente inevitable, PRODUCE trabaja sobre la premisa de que no ocurran descartes en el mar, se identifiquen las áreas de pesca de juveniles al momento del desembarque y así ordenar el cierre preventivo de las mismas con la finalidad de reducir la incidencia de juveniles en las próximas descargas. El proyecto de norma publicado por la RM 376-2016-PRODUCE y que debe ser aprobado en los próximos días, busca fortalecer estas medidas. Una política similar es implementada voluntariamente por un sector importante de la pesca industrial. En las actuales circunstancias, y como se ha señalado en la presentación pública, es preciso ser mucho más cuidadosos dado el riesgo de reducir la capacidad de recuperación del stock. Por ello, el ministro de la Producción ha hecho un llamado a los diversos actores de la pesca para reportar oportunamente las capturas y que se reduzcan los descartes en mar abierto. Adicionalmente, PRODUCE ha autorizado una corta pesca exploratoria que permitiría la identificación de zonas a ser cerradas de forma preventiva antes del inicio de la temporada.

Por otro lado, el tamaño de malla autorizado para la pesca de anchoveta (mínimo de 13 milímetros) permite reducir la captura de los ejemplares más jóvenes (menores de 5 meses, largo inferior a $9,7 \mathrm{~cm}$ ) al mínimo $(<2 \%)$. Esto debería permitir que una porción importante de los peces nacidos en la última temporada reproductiva, sobrevivan la temporada de pesca y lleguen a edad y talla reproductiva durante el próximo verano. Para ello, deben cumplir una condición clave: que la temporada de pesca sea relativamente corta para que no estos ejemplares no alcancen una talla mayor que facilite su capture mientras aún continúe la pesca.

En consecuencia, si la temporada de pesca se extiende demasiado, el riesgo de capturar ejemplares juveniles que entren a la edad adulta aumentaría de manera exponencial, con 


\section{OCEANA Protezeindolos

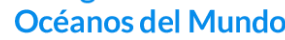

impactos en la recuperación del recurso. Por ello, será preciso maximizar la captura en las primeras semanas de la temporada, siempre previniendo la pesca de juveniles. Esto implica un compromiso entre la eficiencia de la pesca y la conservación del recurso.

\section{REPRODUCCIÓN}

Como se recordará, el inicio de la temporada reproductiva principal de invierno en junio del 2016 motivó el cierre temprano de la primera temporada de pesca. Desde entonces la actividad de puesta de huevos ha sido muy intensa y se ha extendido hasta el mes de octubre a lo largo de casi cinco meses (Ver reporte)

De acuerdo a la información presentada en PRODUCE, la temporada reproductiva ha empezado su fase de declinación según los valores críticos establecidos: la fracción desovante (porcentaje de hembras desovantes muestreadas) ha disminuido por debajo del valor crítico (27,7\% para el periodo invierno-primavera) por lo que se considera que la temporada reproductiva principal ha concluido. Sin embargo, hay que tener en cuenta que según lo reportado por IMARPE a finales de octubre, tanto el índice gonadosomático (la proporción entre el peso de la gónada y el peso eviscerado de hembras), y el índice de atresia (una medida de la reabsorción de los huevos que no llegan a ser expulsados y que indica el final de la temporada principal reproductiva) aún están por encima del promedio.

Por lo tanto, es muy posible que durante las faenas se capturen ejemplares que aún presenten hueveras, indicando que se encuentran en reproducción, situación que puede generar preocupación por considerar que se está afectando al stock. Esto demanda canales de comunicación adecuados con los diversos actores que participan en la pesquería para despejar las dudas que se susciten; y un monitoreo y reporte continuo de la situación reproductiva del stock de parte de IMARPE para tomar medidas rápidas en caso la sostenibilidad del stock lo requiera. 


\section{CONCLUSIONES}

1. Resulta promisorio que el stock de anchoveta muestre signos de recuperación después de las condiciones anómalas sufridas. En buena parte esto se debería a la precaución de haber cerrado la primera temporada de este año de forma temprana para proteger la reproducción del recurso.

2. El principal signo de la recuperación del recurso es la alta proporción de juveniles detectados (86\%). Sin embargo, esto plantea un importante reto de manejo para el gobierno y para el sector privado. Esperamos que con las nuevas medidas que están por aprobarse para reducir el descarte de juveniles (bitácora electrónica, muestreos a bordo, entre otras) se puedan tomar decisiones rápidas que lleven a reducir la pesca de juveniles.

3. Ante las condiciones descritas se requiere del compromiso de las empresas involucradas en la pesquería del recurso para que cumplan con hacer reportes honestos y oportunos. Hay buenas experiencias previas al respecto, es de esperar que con un marco legal favorable y mejores herramientas tecnológicas disponibles se cumplan estas expectativas.

4. Ante la muy probable presencia de ejemplares juveniles y en reproducción, se deben establecer mecanismos de información pública rápidos y promover la transparencia en el acceso a las estadísticas de desembarco, así como los registros de movimiento y actividad de la flota pesquera.

5. En las últimas temporadas han habido avances importantes en cuanto al nivel de transparencia de la información científica que sustenta las decisiones de manejo. Es importante que se continúe con ese esfuerzo, haciendo público el informe del IMARPE a la brevedad posible, y dando continuidad a los reportes de seguimiento y control de la Dirección General de Supervisión y Fiscalización durante el transcurso de la temporada de pesca. 